Data Article

\title{
Identification of primary and secondary metabolites and transcriptome profile of soybean tissues during different stages of hypoxia
}

\author{
Isabel Duarte Coutinho ${ }^{\mathrm{a}, \mathrm{c}, *, 1}$, Liliane Marcia Mert Henning ${ }^{\mathrm{b}, 1}$, \\ Silas Aurelian Döpp ${ }^{c}$, Alexandre Nepomuceno ${ }^{\mathrm{b}}$, \\ Larissa Alexandra Cardoso Moraes ${ }^{\mathrm{b}}$, \\ Juliana Marcolino-Gomes ${ }^{\mathrm{b}}$, Christian Richter ${ }^{\mathrm{c}}$, \\ Harald Schwalbe ${ }^{c}$, Luiz Alberto Colnago ${ }^{\text {a }}$ \\ a Embrapa Instrumentação, Rua XV de Novembro, 1452, São Carlos 13560-970, São Paulo, Brazil

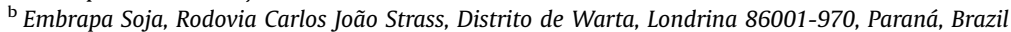 \\ ' Center for Biomolecular Magnetic Resonance, Johann Wolfgang Goethe-University Frankfurt, Max-von \\ Laue-Str. 7, Frankfurt/M. 60438 Germany
}

\section{A R T I C L E I N F O}

Article history:

Received 31 May 2018

Received in revised form

7 July 2018

Accepted 30 September 2018

Available online 15 October 2018

\section{Keywords:}

Soybean

Nuclear magnetic resonance

Primary metabolites

Secondary metabolites

\begin{abstract}
A B S T R A C T
NMR and chromatography methods combined with mass spectrometry are the most important analytical techniques employed for plant metabolomics screening. Metabolomic analysis integrated to transcriptome screening add an important extra dimension to the information flow from DNA to RNA to protein. The most useful NMR experiment in metabolomics analysis is the proton spectra due the high receptivity of ${ }^{1} \mathrm{H}$ and important structural information, through proton-proton scalar coupling. Routinely, databases have been used in identification of primary metabolites, however, there is currently no comparable data for identification of secondary metabolites, mainly, due to signal overlap in normal ${ }^{1} \mathrm{H}$ NMR spectra and natural variation of plant. Related to spectra overlap, alternatively, better resolution can be find using ${ }^{1} \mathrm{H}$ pure shift and 2D NMR pulse sequence in complex samples due to spreading the resonances in a second dimension. Thus, in data brief we provide a catalogue of
\end{abstract}

\footnotetext{
DOI of original article: https://doi.org/10.1016/j.envexpbot.2018.05.018

* Corresponding author at: Embrapa Instrumentação, Rua XV de Novembro, 1452, São Carlos 13560-970, São Paulo, Brazil. E-mail address: isadcoutinho@hotmail.com (I.D. Coutinho).

${ }^{1}$ These authors contributed equally to this work.
} 
metabolites and expression levels of genes identified in soy leaves and roots under flooding stress.

(c) 2018 The Authors. Published by Elsevier Inc. This is an open access article under the CC BY license

(http://creativecommons.org/licenses/by/4.0/).

\section{Specifications table}

Subject area
More specific subject area
Type of data
How data was acquired
Data format
Experimental factors

Experimental features

Data source location Data accessibility Related research article chemistry, biology, agronomy

Metabolomic screening

Table, figure

NMR and RNAseq

Analyzed

$1 D$ and $2 D$ NMR experiments were used for the metabolite annotation.

The LC-DAD-MS was used to support NMR data. Statistical analysis tool such as principal component analysis and variance analysis were performed for physiological and grown parameters and metabolite relative concentration. The expression levels of genes in response to flooding stress was obtained.

The metabolites were assigned from chemical shift and coupling constant data and compared with literature information. The complete assignment was confirmed by 2D NMR information. The retention time and molecular mass data from LC-DAD-MS was helpful for accurate metabolite annotation. The expression of the genes in response to different hypoxia levels was assessed by analysing an RNA-seq library database derived from soybean leaves under flooding stress.

Londrina/Brazil and Frankfurt/Germany

Data is available with this article.

Coutinho ID, Henning, LMM, Döpp SA, Nepomuceno A, Moraes AC, Marcolino-Gomes J, Richter C, Schwalbe H, Colnago LA. Flooded soybean metabolomic analysis reveals importante primary and secondary metabolites involved in the hypoxia stress response and tolerance. Environ. Exp. Bot. 2018 153:176-187.

\section{Value of data}

- The metabolite annotation is useful to be combined with untargeted and target metabolomic approach and might be contributed to a data bank of chemical shift and retention time of primary and secondary metabolites in soybean hydroalcoolic extracts.

- Determine the main metabolic pathway is affected by flooding stress.

- The expression of genes related to the key enzymes involved in the sucrose degradation and alanine and GABA metabolism contribute to explain the metabolic alterations observed in under flooding.

- The resume of variance analysis is important to understand the statistical analysis results.

\section{Data}

Detailed description of metabolite identification in soybean leaves and roots extract, multivariate analysis of secondary metabolites identified in soybean tissues, expression of genes and statistical analysis. 


\section{Experimental design, materials and methods}

\subsection{Sample preparation for metabolomic analysis}

The extracts were obtained according related research article [1,2].

\subsection{Instrumentation}

\subsubsection{NMR analysis}

The spectra were acquired at a temperature of $298 \mathrm{~K}$ on a Avance 600 spectrometer operating at $600,1699 \mathrm{MHz}$ using a $5 \mathrm{~mm}$ Prodigy TCI probe. The ${ }^{1} \mathrm{H}$ pure shift experiment was performed by reset_psyche_1d.pr NMR pulse sequence for homonuclear broadband decoupling $[3,4]$. The spectra were acquired with a $4.50 \mathrm{~s}$ presaturation delay and acquisition time of $3.64 \mathrm{~s}$ (64k points). The chirp pulse were generated in the shape tool of topspin with length of pulse $15 \mathrm{~ms}$, total sweep-width $10 \mathrm{kHz}$, size of shape 10,000 and smoothed in $20 \%$. The gradient pulse aligned with the centre of two chirp pulse was range to $1.0-2.0 \%$. The spectra windows in F1 and F2 were set to 80 and $5 \mathrm{kHz}$, respectively. The number of $\mathrm{t} 1$ (number of chunks) was set to 32-128. The pure shift interferogram was constructed using a script processing provide by Bruker. The ${ }^{1} \mathrm{H}$ 1D NMR experiments were performed according to related research article [1]. Phasing and baseline correction were carried out within the instrument software.

\subsection{2. $\quad$ LC-MS/MS system}

LC-MS/MS system was used to support ${ }^{1} \mathrm{H}$ NMR data. The soybean genotypes BR4 and E45 under control conditions were analysed by LC-DAD-MS using LC-DAD-ESI system consisting of a Shimadzu 20 A HPLC equipped with a LC-20AD quaternary pump, a SPD-M20A photodiode array detector, a SIL$20 \mathrm{~A}$ thermostated autosampler and a CTO-20A column compartment, coupled to a Bruker Ion Trap, with a heated ESI source. UV spectra were acquired from 230 to $400 \mathrm{~nm}$. Mass spectra were acquired in negative and positive modes over $\mathrm{m} / \mathrm{z}$ range of $100-1000$, in separated runs. Operating parameters were as follow: source voltage, $4.5 \mathrm{kV}$, sheath gas, $9.00 \mathrm{~L} / \mathrm{min}$ dry gas, 40 psi nebulizer and dry temperature, $300^{\circ} \mathrm{C}$. Automatic MS-MS was performed on the three most abundant ions of each scan. An isolation width of $m / z 3$ was used and precursors were fragmented by CID with normalized collision energy of 60. The data analyses were performed using Data Analysis software. The chromatographic runs were performed using Kinetex ${ }^{\circledR} \mathrm{C}-18$ column $(1.9 \mu \mathrm{m}, 30 \times 2.1 \mathrm{~mm}$ i.d., Phenomenex $)$, which was maintained at $25{ }^{\circ} \mathrm{C}$. The gradient of elution was performed with water $/ 0.1 \%$ formic acid (A) and acetonitrile $/ 0.1 \%$ formic acid (B) under the following conditions: $0 \mathrm{~min}, 5 \% \mathrm{~B} ; 30 \mathrm{~min}, 40 \% \mathrm{~B}$; $35 \mathrm{~min}, 100 \% \mathrm{~B} ; 40 \mathrm{~min}, 100 \% \mathrm{~B}$. Flow rate at $1.0 \mathrm{~mL} / \mathrm{min}$ and injection volume of $1 \mu \mathrm{L}$.

\subsection{Data analysis}

The ${ }^{1} \mathrm{H}$ NMR data ranging from 6.00 to $8.50 \mathrm{ppm}$ were converted to ASCII files using Bruker TopSpin 3.5. The data preprocessing and Principal Component Analysis (PCA) from ${ }^{1} \mathrm{H}$ NMR were performed using MATLAB R2016b and PLS-Toolbox. The data analysis was performed according related research article [1].

\subsection{Gene expression analysis}

RNAseq libraries of soybean roots under hypoxic stress, obtained by Nakayama et al. [5] and were used in this study. The experimental design consisted of two soybean cultivars (BR4 and E45) submitted to different stress durations: $0.5 \mathrm{~h}, 4 \mathrm{~h}$, and $28 \mathrm{~h}$ [1].

\subsection{Statistical analysis}

Data from physiological parameters, biomass accumulation, and metabolomic analysis showed a normal distribution and were submitted to the analysis of variance [1]. 


\section{Data analysis}

\subsection{Metabolite identification}

The metabolites identified were valine (1) $\delta 0.99$ of $6 \mathrm{H}(\mathrm{d}, 7.0)$, ethanol (2) $\delta 1.19$ of $3 \mathrm{H}(\mathrm{t}, 7.6)$, lactate (3) $\delta 1.33$ (d, 1.33), hydroxybutyrate (4) $\delta 1.34(\mathrm{~s})$, alanine (5) $\delta 1.48$ of $3 \mathrm{H} \mathrm{(d,} \mathrm{7.3),} \mathrm{GABA} \mathrm{(6)}$ $\delta 1.883 \mathrm{H}(\mathrm{q}, 7.2), \delta 2.30$ of $2 \mathrm{H}(\mathrm{t}, 7.5), \delta 2.99$ of $2 \mathrm{H}(\mathrm{t}, 7.5)$, acetate (7) $\delta 1.89$ of $3 \mathrm{H}(\mathrm{s})$, glutamic acid (8) $\delta 2.05$ of $3 \mathrm{H}(\mathrm{m}), \delta 2.14$ of $3 \mathrm{H}(\mathrm{m}), \delta 2.35(\mathrm{~m})$, asparagine (12) $\delta 2.86(\mathrm{dd}, 7.9,16.6)$, lysine $\delta 3.03$ of $3 \mathrm{H}$ $(t, 7.5)$ and glycine (15) $\delta 3.57$ (s) of $2 \mathrm{H}$. Malic acid (9) succinic acid (12), citric acid (13), choline (15), pinitol (17), myo-inositol (18), fumarate (27) and formic acid (39) were assigned using the signals at $2.36(\mathrm{q}, 9.6), 2.38(\mathrm{~s}), 2.38(\mathrm{~s}), 2.53(\mathrm{~d}, 16.6), 3.19(\mathrm{~s}), 3.59(\mathrm{~s}), 3.60(\mathrm{t}, 9.4), 6.49(\mathrm{~s})$ and $8.44(\mathrm{~s}) \mathrm{ppm}$, respectively. $\beta$-glucose (19) and $\alpha$-glucose (21) were identified using the characteristic signals of the anomeric protons at $4.61(\mathrm{~d}, 7.91)$ and $5.20(\mathrm{~d}, 3.9)$. Fructose $(18)$ was assigned using the signal at $\delta$ $3.99(\mathrm{dd}, 2.7,10.0)$, sucrose $(23)$ at $\delta 5.39(\mathrm{~d}, 4.0)$ and trehalose $(20)$ at $\delta 5.19(\mathrm{~d}, 4.6)$.

The signal from $\delta 6$ to 10 were attributed to phenylpropanoids and identified four hydroxycinnamic acids, four flavonols and three isoflavones, which had the structure confirmed by 1D and 2D NMR, LC-DAD-MS/MS experiments. The metabolites trans-3-caffeoylquinic acid (24), cis-3-caffeoylquinic (23), trans-coumaroylquinic acid (26) and cis-coumaroylquinic acid (25) were identified in mixture based on differences intensity of $\mathrm{H}^{\prime} / \mathrm{6}^{\prime}$. The characteristic signals of hydroxycinnamic derivatives were detected as pairs of doublets at $\delta 6.06 / 7.07$ and 6.54/7.81, corresponding to cis-pcoumaric acid and trans-p-coumaric acid, $\delta$ 6.51/7.74 and 5.93/7.16 corresponding to trans-caffeoyl and cis-caffeoyl acid (31), due to coupling of the olefinic protons with $\mathrm{Z}$ (trans, $J=16.0 \mathrm{~Hz}$ ) and $\mathrm{E}$ (cis, $J=12.0 \mathrm{~Hz}$ ) configurations (Figure SM3). The COSY and J-Resolved experiments were useful for confirming the presence of signals from a pair olefinic hydrogens from compound 26 that overlapped with the intense signal of fumaric acid $(\delta 6.53 \mathrm{~s})$. The presence of hydroxycinnamic acid derivatives was supported by UV due to a characteristic absorbance at 300-330 nm corresponding to cinnamoyl systems and confirmed by LC-MS/MS analysis. The compounds 23-26 come out at retention time 4.8, 5.5, 6.4 and $7.2 \mathrm{~min}$. Trans/cis-caffeoylquinic acid and trans/cis-coumaroylquinic acid had precursor ion $m / z 371$ [M-H-18] $]^{-}$and $m / z 355$ [M-H-18] $]^{-}$. The MS/MS spectra of isomers showed a base peak product ion of $m / z 191$ [quinate-H] ${ }^{-}$.

Five kaempferol glucosides were identified, three of which are kaempferol triglucosides and two diglucosides. Kaempferol derivatives showed 2 peaks at $\delta 6.56(3 \mathrm{H}, \mathrm{d}, J=1.8 \mathrm{~Hz})$ and $6.34 \mathrm{ppm}(3 \mathrm{H}, \mathrm{d}$, $J=1.8 \mathrm{~Hz}$ ) consistent with the meta protons $\mathrm{H}-6$ and $\mathrm{H}-8$ on A-ring and an $\mathrm{AA}^{\prime} \mathrm{BB}^{\prime}$ system at 8.07/7.99 $\left(6 \mathrm{H}, \mathrm{d}, 8.6 \mathrm{~Hz}, \mathrm{H}-2^{\prime}, 6^{\prime}\right)$ and $7.00\left(6 \mathrm{H}, \mathrm{d}, 8.8 \mathrm{~Hz}, \mathrm{H}-3^{\prime}, 6^{\prime}\right)$ corresponding to the protons on B-ring of aglycone.

Homonuclear scalar couplings corresponding to phenolic acids and kaempferol derivatives were collapsed in singlet lines and significantly improved resolution in aromatic region, allowing the assignment of three kaempferol isomers $(28,29,30)$ due to presence of three singlet lines at $8.0 \mathrm{ppm}$ corresponding to $\mathrm{J}_{\mathrm{A}^{\prime} \mathrm{X}^{\prime}}$ system (Fig. 4). The phenolic compounds occur in low concentration in plants and aromatic region spectra showed the cost of sensitivity using pure shift method, but maintains advantage of obtaining simplified singlet resonances. Therefore, the better resolution of pure shift methods reveals the potential of PSYCHE 1D as deconvolution tool.

Kaempferol-3-O- $\alpha$-rhamnosyl-di- $\beta$-glucoside isomer I (28) was identified as major compound, the sugar moiety shows two overlapped proton signals at $4.72(1 \mathrm{H}, \mathrm{d}, J=7.5)$ corresponding to two anomeric proton of a $\beta$-glucosyl $\left(\mathrm{H}-1^{\prime \prime} / 1^{\prime \prime \prime}\right)$ and a methyl signal $1.12(3 \mathrm{H}, \mathrm{d}, J=6.2 \mathrm{~Hz})$ in the high-field region was assigned to rhamnose and $4.39(1 \mathrm{H}, \mathrm{d}, J=1.0)$ were assignable to the $\mathrm{H}-1$ of an $\alpha$-rhamnosyl proton. In the ${ }^{1} \mathrm{H}$ and ${ }^{13} \mathrm{C}$ NMR values for all the carbons were assigned on the basis of HSQC and are given in Table 1 . The placement of the sugar unit was established at C-3 position on the basis UV spectra $\lambda_{\max }$ of $265-345 \mathrm{~nm}$ indicative that hydroxyl at C-3 is not free. In addition, the structure was further supported by of key HMBC correlations C-4 and H1". The LC-MS/MS analysis was employed to support NMR data and the Kaempferol-3-O- $\alpha$-rhaminosyl-di- $\beta$-glucoside isomer showed $[\mathrm{M}+\mathrm{H}]^{+}$peak at $\mathrm{m} / z 757$ eluted at $14 \mathrm{~min}$. The MS/MS spectra showed ions $\mathrm{m} / z$ 611, 595 and 287 in positive mode. The fragment ion $\mathrm{m} / z 611$ corresponds to cleavage of glycoside bond (loss of 


\section{Table 1}

Chemical shifts $(\delta)$ and coupling constants $(\mathrm{Hz})$ of the primary metabolites identified in hydroalcoholic extracts of soybean roots and leaves.

\begin{tabular}{|c|c|c|}
\hline Metabolite & $\delta^{1} \mathbf{H}$ (multiplicity, J Hz) & ${ }^{13} \mathrm{C}$ (HSQC) \\
\hline Valine (1) & 0.99 (d, 7.0), $2.27(\mathrm{~m})$ & - \\
\hline Ethanol (2) & $1.33(\mathrm{~d}, 6.6)$ & \\
\hline Lactate (3) & $1.33(\mathrm{~d}, 6.6)$ & - \\
\hline Hydroxyisobutyrate (4) & $1.34(\mathrm{~s})$ & 23.9 \\
\hline Alanine (5) & $1.46(\mathrm{~d}, 7.4)$ & 17.9 \\
\hline GABA (6) & $\overline{1.88}(\mathrm{q}, 7.2), \underline{2.30}(\mathrm{t}, 7.4), 2.99(\mathrm{t}, 7.5)$ & $24.9,35.7$ \\
\hline Acetate (7) & $1.89(\mathrm{~s})$ & - \\
\hline Glutamic acid (8) & $2.05(\mathrm{~m}), 2.14(\mathrm{~m})$ & 29.7 \\
\hline Malic acid (9) & $\underline{2.36}(\mathrm{q}, 9.6,15.3), 2.66(\mathrm{dd}, 15.3,3.5)$ & 43.6 \\
\hline Succinic acid (10) & $\overline{2.38}(\mathrm{~s})$ & 33.0 \\
\hline Citric acid (11) & $\overline{2.53}(\mathrm{~d}, 16.6)$ & 47.1 \\
\hline Asparagine (12) & $2.86(\mathrm{dd}, 7.9,16.6), 2.96(\mathrm{dd}, 4.2,12.2)$ & - \\
\hline Lysine (13) & $3.03(t, 7.5)$ & - \\
\hline Choline (14) & $\underline{3.19}(\mathrm{~s})$ & - \\
\hline Glycine (15) & $\overline{3.57}(\mathrm{~s})$ & - \\
\hline Pinitol (16) & $3.59(\mathrm{~s})$ & 61.1 \\
\hline Myo-inositol (17) & $3.60(\mathrm{t}, 9.4), 4.11(\mathrm{sbr})$ & - \\
\hline Fructose (18) & $4.19(\mathrm{~d}, 3.6)$ & 100.8 \\
\hline$\beta$-Glucose (19) & $\underline{4.61}(\mathrm{~d}, 7.9)$ & 97.4 \\
\hline Trehalose (20) & $\overline{5.19}(\mathrm{~d}, 4.6)$ & 76.1 \\
\hline$\alpha$-Glucose (21) & $\underline{5.20}(\mathrm{~d}, 3.9)$ & 93.5 \\
\hline Sucrose (22) & $\overline{5.39}(\mathrm{~d}, 4.0), 4.19(\mathrm{~d}, 8.8)$ & 92.1 \\
\hline $\begin{array}{l}\text { cis-caffeoylquinic acid } \\
(23)^{\mathrm{L}}\end{array}$ & $\begin{array}{l}5.90(\mathrm{H} 8, \mathrm{~d}, 12.4), 6.72(\mathrm{H} 2, \mathrm{~d}, 8.2), 6.96(\mathrm{H} 6, \mathrm{dd}, 8.2,2.0) \\
7.03(\mathrm{H} 5, \mathrm{~d}, 2.0), 7.16(\mathrm{H} 7, \mathrm{~d}, 12.2)^{\mathrm{a}}\end{array}$ & - \\
\hline $\begin{array}{l}\text { trans-caffeoylquinic acid } \\
\qquad(24)^{\mathrm{L}}\end{array}$ & $\begin{array}{l}6.49(\mathrm{H} 8, \mathrm{~d}, 16.0), 6.71(\mathrm{H} 2, \mathrm{~d}, 8.2), 6.99(\mathrm{H} 6, \mathrm{dd}, 8.2,2.0) \\
7.07(\mathrm{H} 5, \mathrm{~d}, 2.0), 7.80(\mathrm{H} 7, \mathrm{~d}, 16.0){ }^{\mathrm{a}}\end{array}$ & \\
\hline $\begin{array}{l}\text { cis-p-coumaroylquinic } \\
\quad \text { acid }(25)^{\mathrm{L}}\end{array}$ & $\begin{array}{l}6.07(\mathrm{H} 8, \mathrm{~d}, 12.3), 7.09(\mathrm{H} 7, \mathrm{~d}, 12.6), 6.86\left(\mathrm{H}^{\prime} 5^{\prime}, \mathrm{d}, 8.4\right) \\
7.59\left(\mathrm{H} 2^{\prime}, 6^{\prime}, \mathrm{d}, 8.3\right), 5.42\left(\mathrm{H} 1^{\prime \prime}, \mathrm{d}, 1.3\right) .^{\mathrm{a}}\end{array}$ & $\begin{array}{l}117.5(\mathrm{C} 8), 146.7(\mathrm{C} 7), 116.4\left(\mathrm{C} 3^{\prime}, \mathrm{C}^{\prime}\right) \\
133.2\left(\mathrm{C} 2^{\prime}, \mathrm{C}^{\prime}\right), 74.7\left(\mathrm{C}^{\prime \prime}\right)\end{array}$ \\
\hline $\begin{array}{l}\text { trans- } p \text { - coumaroylquinic } \\
\quad \text { acid }(26)^{\mathrm{L}}\end{array}$ & $\begin{array}{l}6.42(\mathrm{H} 8, \mathrm{~d}, 16.0), 7.75(\mathrm{H} 7, \mathrm{~d}, 16.0), 6.92\left(\mathrm{H}^{\prime} 5^{\prime}, \mathrm{d}, 8.4\right) \\
7.59\left(\mathrm{H} 2^{\prime}, 6^{\prime}, \mathrm{d}, 8.3\right){ }^{\mathrm{a}}\end{array}$ & $\begin{array}{l}115.6(\mathrm{C} 8), 147.7(\mathrm{C} 7), 115.2\left(\mathrm{C}^{\prime}, \mathrm{C}^{\prime}\right) \\
131.9\left(\mathrm{C} 2^{\prime}, \mathrm{C}^{\prime}\right), 74.6\left(\mathrm{C}^{\prime \prime}\right)\end{array}$ \\
\hline Fumarate (27) & $6.49(\mathrm{~s})$ & 136.8 \\
\hline $\begin{array}{l}\text { Kaempferol-3-O- } \alpha \text {-rham- } \\
\text { nosyl-di- } \beta \text {-glucoside } \\
\text { isomer I }(28)^{\mathrm{L}}\end{array}$ & $\begin{array}{l}6.56 \text { (H6, d, 1.8), } 6.34 \text { (H8, d, 1.9), } 7.00\left(\mathrm{H}^{\prime} 5^{\prime}, \mathrm{d}, 8.6\right), 8.07 \\
\left(\mathrm{H} 2^{\prime} 6^{\prime}, \mathrm{d}, 8.8\right), 4.72\left(\mathrm{Glu}-\mathrm{H} 1^{\prime \prime} / \mathrm{Glu}-\mathrm{H} 1^{\prime \prime \prime}, \mathrm{d}, 7.5\right), 4.39 \text { (Rha- } \\
\left.\mathrm{H} 1^{\prime \prime \prime \prime}, \mathrm{d}, 1.0\right), 1.11 \text { (Rha-H6"', d, 6.2). }{ }^{\mathrm{a}}\end{array}$ & $\begin{array}{l}96.6(\mathrm{C} 8), 101.9(\mathrm{C} 6), 131.5\left(\mathrm{C} 2^{\prime}, 6^{\prime}\right), \\
115.7\left(\mathrm{C} 3^{\prime}, 6^{\prime}\right), 99.6\left(\mathrm{C} 1^{\prime \prime}\right), 100.7\left(\mathrm{C} 1^{\prime \prime \prime}\right), \\
16.5\left(\mathrm{C} 6^{\prime \prime \prime}\right), 79.3\left(\mathrm{C} 5^{\prime \prime}\right) .\end{array}$ \\
\hline $\begin{array}{l}\text { Kaempferol-3-O- } \alpha \text {-rham- } \\
\text { nosyl-di- } \beta \text {-glucoside } \\
\text { isomer II }(29)^{\mathrm{L}}\end{array}$ & 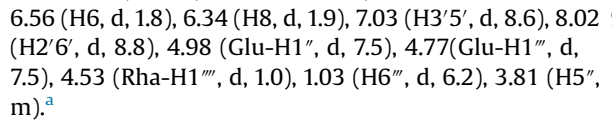 & $\begin{array}{l}96.6(\mathrm{C} 8), 101.9(\mathrm{C} 6), 131.5\left(\mathrm{C} 2^{\prime}, 6^{\prime}\right), \\
115.7\left(\mathrm{C} 3^{\prime}, 6^{\prime}\right), 100.2\left(\mathrm{C} 1^{\prime \prime}\right), 100.8\left(\mathrm{C} 1^{\prime \prime \prime}\right), \\
16.5\left(\mathrm{C} 6^{\prime \prime \prime}\right), 79.3\left(\mathrm{C} 5^{\prime \prime}\right) .\end{array}$ \\
\hline $\begin{array}{l}\text { Kaempferol-3-O- } \alpha \text {-di- } \\
\text { rhaminosyl- } \beta \text {-glucoside } \\
(30)^{\mathrm{L}}\end{array}$ & $\begin{array}{l}\text { 6.56 (H6, d, 1.8), } 6.34(\mathrm{H} 8, \mathrm{~d}, 1.9), 7.03\left(\mathrm{H}^{\prime} 5^{\prime}, \mathrm{d}, 8.6\right), 8.04 \\
\left(\mathrm{H} 2^{\prime} 6^{\prime}, \mathrm{d}, 8.8\right) .{ }^{\mathrm{a}}\end{array}$ & \\
\hline $\begin{array}{l}\text { Kaempferol-O- } \alpha \text {-rhami- } \\
\text { nosyl- } \beta \text {-glucoside }(31)^{\mathrm{L}}\end{array}$ & $\begin{array}{l}\text { 6.56 (H6, d, 1.8), } 6.34 \text { (H8, d, 1.9), } 7.03\left(\mathrm{H}^{\prime} 5^{\prime}, \mathrm{d}, 8.6\right), 8.02 \\
\left(\mathrm{H} 2^{\prime} 6^{\prime}, \mathrm{d}, 8.8\right), 5.45 \text { (Glu-H1', d, 7.5), } 4.51 \text { (Rha-H1 } 1^{\prime \prime \prime}, \mathrm{d}, \\
1.0) .^{\mathrm{a}}\end{array}$ & - \\
\hline Daidzein $(32)^{\mathrm{R}}$ & $\begin{array}{l}6.83 \text { (H8, d, 1.9), } 6.93 \text { (H6, dd, 2.2, 8.8), } 7.80 \text { (H5, d, 8.8), } \\
6.99\left(\mathrm{H}^{\prime}, 5^{\prime}, \mathrm{d}, 8.5\right), 7.41\left(\mathrm{H} 2^{\prime}, 6^{\prime}, \mathrm{d}, 8.5\right), 8.13(\mathrm{H} 2, \mathrm{~s}) .^{\mathrm{a}}\end{array}$ & - \\
\hline Daidzin $(33)^{R}$ & $\begin{array}{l}7.31 \text { (H8, d, 1.9), } 7.24 \text { (H6, dd, 2.2, 8.9), 7.80 (H5, d, 8.9), } \\
6.97\left(\mathrm{H}^{\prime}, 5^{\prime}, \mathrm{d}, 8.5\right), 7.40\left(\mathrm{H} 2^{\prime}, 6^{\prime}, \mathrm{d}, 8.5\right), \underline{8.13}(\mathrm{H} 2, \mathrm{~s}) \\
5.25 \text { (Glu-H1", d, 7.2). }\end{array}$ & $\begin{array}{l}101.0(\mathrm{C} 8), 115.7(\mathrm{C} 6), 127.7(\mathrm{C} 5), 154.5 \\
(\mathrm{C} 2), 115.5\left(\mathrm{C}^{\prime}, 5^{\prime}\right), 130\left(\mathrm{C} 2^{\prime}, 6^{\prime}\right)\end{array}$ \\
\hline Malonyldaidzin $(34)^{\mathrm{R}}$ & $\begin{array}{l}7.30(\mathrm{H} 8, \mathrm{~d}, 2.0), 7.25(\mathrm{H} 6, \mathrm{dd}, 2.2,8.2), 6.97\left(\mathrm{H}^{\prime}, 5^{\prime}, \mathrm{d}\right. \\
8.5), 7.37\left(\mathrm{H} 2^{\prime}, 6^{\prime}, \mathrm{d}, 8.5\right), \underline{8.14}(\mathrm{H} 2, \mathrm{~s})\end{array}$ & \\
\hline Formic acid (35) & $8.44(\mathrm{~s})$ & - \\
\hline Trigoneline $(36)^{\mathrm{L}}$ & $9.12(\mathrm{~s})$ & - \\
\hline
\end{tabular}

a Supported by LC-MS/MS data. L: detected only in leaf extract. R: detected only in root extract. The underlined signals were used to obtain the relative metabolite concentrations. 

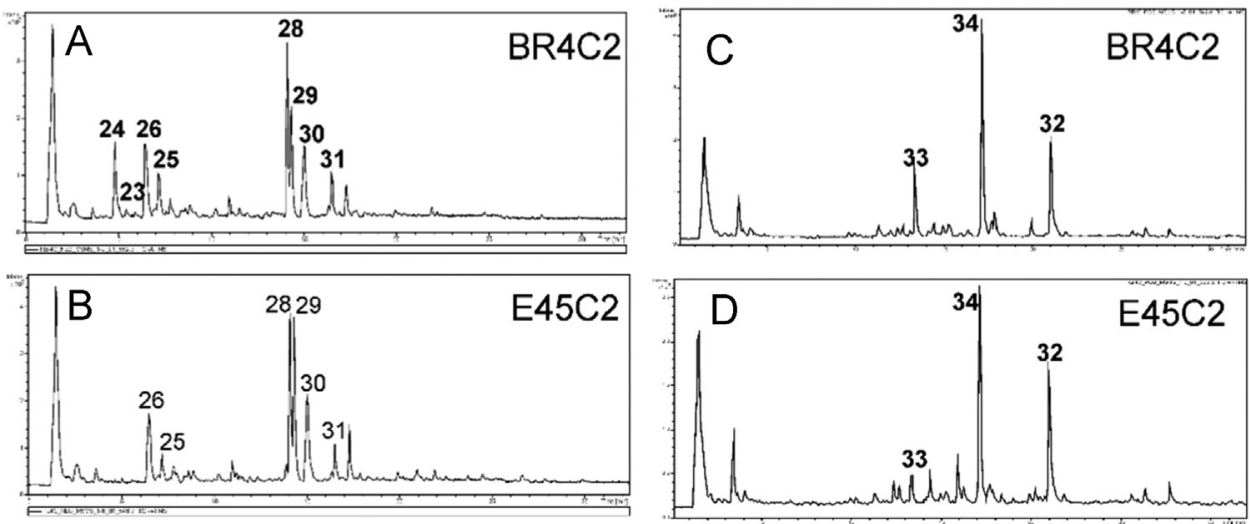

Fig. 1. Total Ion Chromatogram (TIC) of hydro alcoholic extract of soybean leaves (A, B) and roots (C, D).
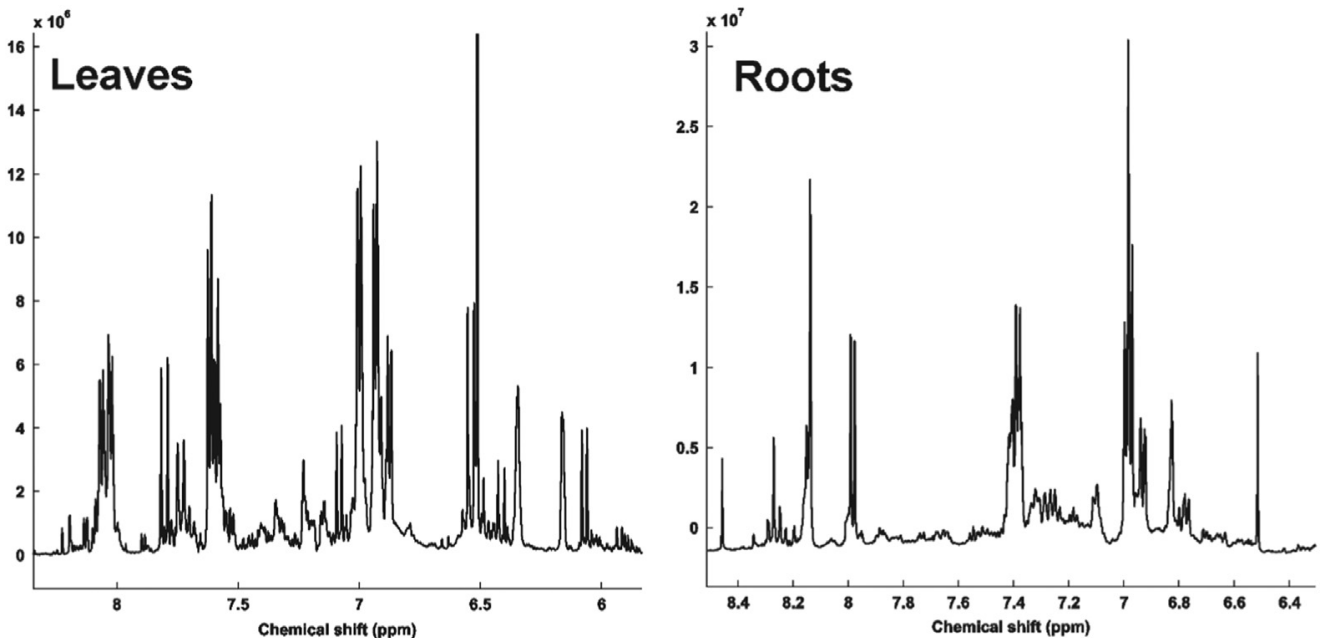

Fig. 2. Mean ${ }^{1} \mathrm{H}$ NMR spectra region $6.00-8.50 \mathrm{ppm}$ corresponding to main secondary metabolites identified in soybean extract and selected for PCA.

$146 \mathrm{Da}$ - indicative of an arabinosyl moiety), $\mathrm{m} / \mathrm{z} 595$ corresponds loss of $162 \mathrm{Da}$ indicative of a glucosyl moiety and $m / z 287$ is relative to aglycone Kaempferol.

Kaempferol-3-O- $\alpha$-rhamnosyl-di- $\beta$-glucoside isomer II (29) presented the same signal patterns of compound 28, except to downfield shift of the $\mathrm{H}-2^{\prime}, 6^{\prime}$ proton $(8.02 \mathrm{ppm})$, as well as high field shift of the corresponding $\beta$-glucoside anomeric proton at $4.98(1 \mathrm{H}, \mathrm{d}, 7.4 \mathrm{~Hz})$ and $4.77(1 \mathrm{H}, \mathrm{d}, 7.7 \mathrm{~Hz})$, with respect to the Kaempferol-3-O- $\alpha$-rhaminosyl-di- $\beta$-glucoside I. The C-5"' signal (79.3) of glucose showed a downfield shift of $2.3 \mathrm{ppm}$ in comparison with the corresponding C-5"' signal (77.1) of isomer I, indicating the difference of both kaempferol triglucosides is due to conformation of hydroxyl at $\mathrm{C5}^{\prime \prime}$ position. Kaempferol triglucoside isomer II showed $[\mathrm{M}+\mathrm{H}]^{+}$peak at $\mathrm{m} / \mathrm{z} 757$ eluted at 14.3 $\mathrm{min}$. The MS/MS spectra showed similar fragment ions $\mathrm{m} / z 595$ and 287 in positive mode compare to isomer I. The fragment ion $\mathrm{m} / \mathrm{z} 595$ corresponds to cleavage of glycoside bond (loss of $146 \mathrm{Da}-$ indicative of an glucosyl moiety) and $m / z 287$ is relative to aglycone Kaempferol.

Kaempferol-3-O- $\alpha$-di-rhaminosyl- $\beta$-glucoside (30) presented the same signal patterns of compounds 28 and 29, except to downfield shift of the H-2',6' proton $(8.04 \mathrm{ppm})$. The presence of 
compound $\mathrm{x}$ was supported by LC-MS/MS data from peak at 15 min with a pseudomolecular ion $\mathrm{m} / \mathrm{z}$ $741[\mathrm{M}-\mathrm{H}]^{-}$. The MS/MS spectrum (negative mode) showed ions $\mathrm{m} / z 595$ and 444 related to cleavage of the two rhamnosyl units and $\mathrm{m} / z 287$ corresponding to cleavage of the glucosyl linkage.

Kaempferol-3-O- $\alpha$-rhamnoside- $\beta$-glucoside (31) showed the same aglycone signal patterns of compound 28 in aromatic region, one anomeric proton signals at $5.45(1 \mathrm{H}, \mathrm{d}, J=3.73)$ was assignable to $\mathrm{H}-1$ of a $\alpha$-glucosyl proton and 4.51 corresponding to rhaminosyl moiety. The compound 31 was identified in with retention time $16.5 \mathrm{~min}$ in the total ion chromatogram with a pseudomolecular ion $m / z 595[\mathrm{M}+\mathrm{H}]^{+}$. The MS/MS spectrum showed ions $\mathrm{m} / z 433$ and 287 related to cleavage of the rhamnosyl and glucosyl linkage, respectively.

Daidzein (32), daidzin (33) and malonyldaidzin (34) were identified as major isoflavones from extract of soybean roots (Figure SM2). These isoflavones are common in soybean tissues and the Table 1 shows complete assignment based on literature [8].

The fluctuation of isoflavones concentration in ${ }^{1} \mathrm{H}-\mathrm{NMR}$ spectrum of $\mathrm{Br} 4 \mathrm{C}$ genotypes was fundamental to spectral assignment due to intensity differences of $\mathrm{H}-2$ and $\mathrm{H}-5$ in a clearly downfield region. The aglycone Daidzein was identified as major and showed 3 signals at $\delta 6.83(1 \mathrm{H}, \mathrm{d}, J=1.9$ $\mathrm{Hz}), 6.93(1 \mathrm{H}, \mathrm{dd}, J=2.2,8.8 \mathrm{~Hz})$ and $7.98(1 \mathrm{H}, \mathrm{d}, J=8.8 \mathrm{~Hz})$ characteristic with trisubstituted system on A-ring, 2 signals corresponding to $\mathrm{AA}^{\prime} \mathrm{BB}^{\prime}$ system at $\delta 6.97(2 \mathrm{H}, \mathrm{d}, 8.1 \mathrm{~Hz})$ and $7.37(2 \mathrm{H}, \mathrm{d}, 8.1 \mathrm{~Hz})$
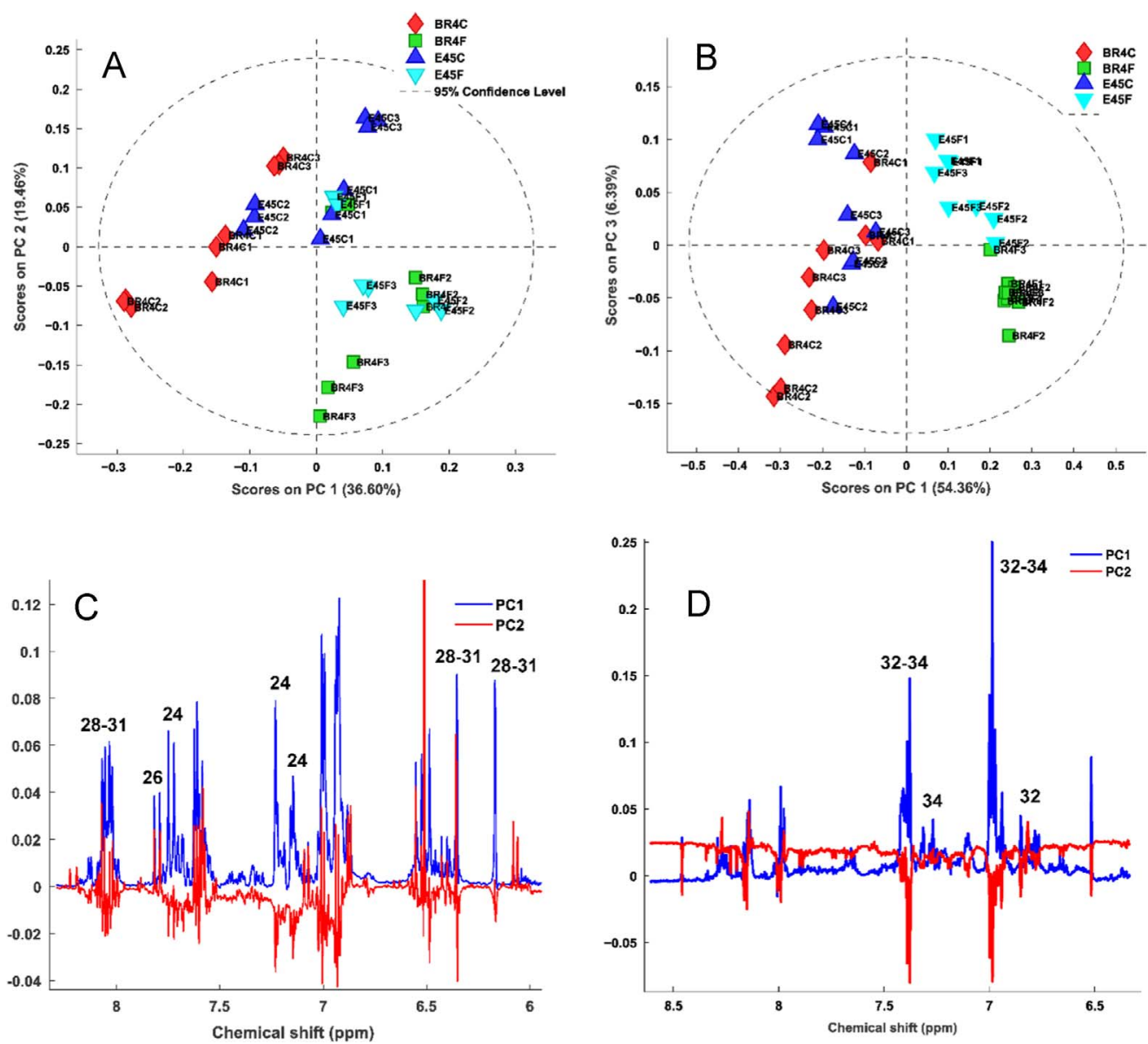

Fig. 3. Principal Component Analysis based on ${ }^{1} \mathrm{H}$ NMR spectra of soybean tissues. (A) Scores plot performed from ${ }^{1} \mathrm{H}$ NMR spectra ( $\delta 6.00-8.50)$ of hydroalcoholic extract of soybean leaves and roots (B). (C) PC1 versus PC3 loadings plot performed from ${ }^{1} \mathrm{H}$ NMR spectra ( $\left.86.00-8.50\right)$ of hydroalcoholic extract of soybean leaves and roots (D). 
and signal $\delta 8.13$ corresponding to $\mathrm{H}-2$, latter characteristic of isoflavone. The glucosides isoflavones Daidzin and malonyldaidzin presented the same signal patterns of Daidzein corresponding to $\mathrm{AA}^{\prime} \mathrm{BB}^{\prime}$ system on B-ring. Daidzin showed characteristic signals corresponding to trisubstituted system on Aring at $\delta 7.24(1 \mathrm{H}, \mathrm{dd}, J=2.2,8.9 \mathrm{~Hz}, \mathrm{H}-6)$ and $7.31 \mathrm{ppm}(1 \mathrm{H}, \mathrm{d}, J=2.2 \mathrm{~Hz}, \mathrm{H}-8)$. The sugar moiety showed signal at $5.25 \mathrm{ppm}(1 \mathrm{H}, \mathrm{d}, 7.2 \mathrm{~Hz})$ and was assignable to $\mathrm{H}-1$ of a $\beta$-glucosyl proton. Malonyldaidzin shows the same signals patterns of Daidzin, except to downfield shift of $\mathrm{H}-8$ at $7.30(1 \mathrm{H}$, $\mathrm{d}, 2.8 \mathrm{~Hz})$ and $\mathrm{H}-6$ at $7.25 \mathrm{ppm}(1 \mathrm{H}, \mathrm{dd}, 2.2$ and $8.2 \mathrm{~Hz})$. The major isoflavones identified by ${ }^{1} \mathrm{H}-\mathrm{NMR}$ were confirmed using LC-DAD-MS/MS data. Daidzin, malonyldaidzin and daidzein were eluted at $13.4,17.0$ and $21.0 \mathrm{~min}$. This was corroborated by the sequence of elution from C-18, compounds glycosides elute before than aglycone. Daidzin was identified had precursor ion $m / z 417[\mathrm{M}+\mathrm{H}]^{+}$. MS/ MS of $m / z 417$ showed a peak at $m / z 255$ corresponding to aglycone daidzein. Malonyldaidzin showed $[\mathrm{M}-\mathrm{H}]^{-}$peak at $m / z 501$ and a base peak product ion of $m / z 253$ [M-248 $^{-}$corresponding to aglycone daidzein (Fig. 1).

\section{Multivariate analysis of secondary metabolites identified in hydroalcoolic extracts of soybean tissues}

See Figs. 2-4 and Table 2.

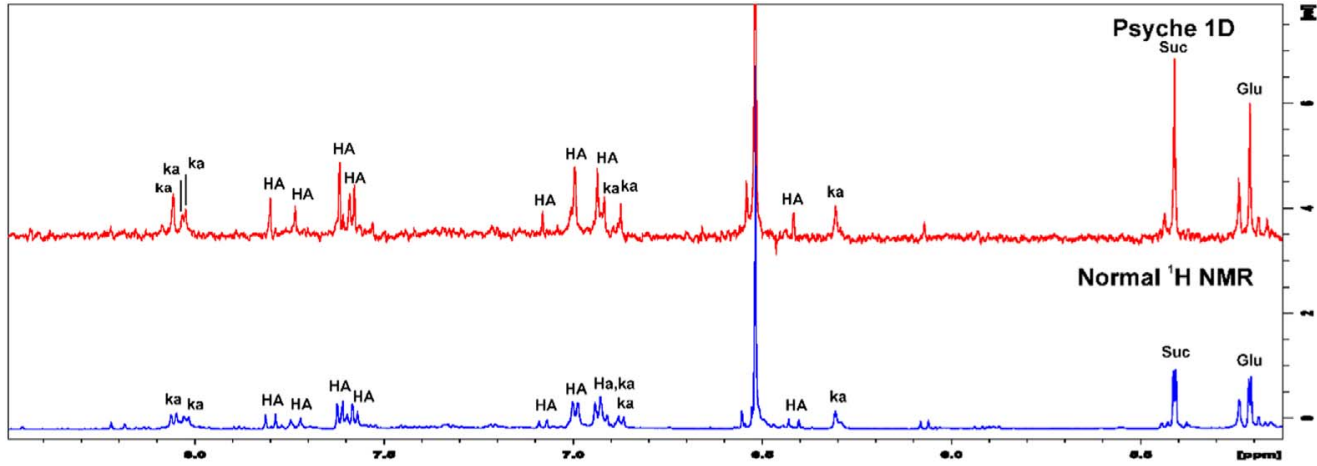

Fig. 4. ${ }^{1} \mathrm{H}$ and $1 \mathrm{D}$ PSYCHE spectrum of alcoholic soybean leaves extract in $\mathrm{D}_{2} \mathrm{O} / \mathrm{MEOD}(8: 2 \mathrm{v} / \mathrm{v})$. The region between 5.00 and $8.50 \mathrm{ppm}$ corresponding to chemical shift of phenolic compounds identified. HA (hydroxycinnamic acids) and Kaempferol (Ka) derivatives.

Table 2

Resume of variance analysis performed for physiological and grown parameters: Stomatal conductance (Gs), Photosynthesis (A), Chlorophyll (CH), Roots dry matter (RDM), Shoot dry matter (SDM) and Total plant dry matter (TDM). (SV) Source of Variation; (DF) Degrees of freedom.

\begin{tabular}{|c|c|c|c|c|c|c|c|}
\hline \multirow[t]{2}{*}{ S.V } & \multirow[t]{2}{*}{ D.F } & \multicolumn{6}{|c|}{ Mean square (MS) } \\
\hline & & Gs & A & Chlorophyll & RDM & SDM & TDM \\
\hline G & 1 & $0.06615^{*}$ & 44.9634 & $0.000041^{*}$ & $0.481667^{*}$ & 0.357704 & $1.669538^{*}$ \\
\hline WC & 1 & $0.176817^{*}$ & 477.6660 & $0.000386^{*}$ & $0.260417^{*}$ & 3.658204 & 5.870704 \\
\hline$G^{*} W C$ & 1 & 0.01215 & 0.110704 & 0.000005 & 0.016017 & 0.175104 & 0.297037 \\
\hline Error & 8 & 0.003603 & 5.708316 & 0.000006 & 0.014932 & 0.069369 & 0.127891 \\
\hline $\mathrm{CV}$ & & 30.65 & 23.08 & 26.51 & 16.78 & 19.92 & 17.44 \\
\hline Mean & & 0.195833 & 10.35042 & 0.009425 & 0.728333 & 1.322083 & 2.050417 \\
\hline
\end{tabular}

" $P$ value $<0.05$ 


\section{Expression levels of genes}

The expression ratio (fold-change, $\mathrm{fc}$ ) of genes was performed by dividing transcript abundance values (in RPM $=$ Reads per Mapped Million) from plants under hypoxic and normoxic conditions. The statistical significance of DEGs were obtained by using Bioconductor package edgeR [6], corrected by Benjamini and Hochberg method [7]. We only considered as DEGs those showing fold-change _ 2 (up), _- 2 (down), adj. pvalue _ 0.01, and with more than 20 mapped reads (RPM _ 9) in at least one of the two compared libraries. See Table 3.

\section{Table 3}

Expression levels of genes involved in sucrose degradation and alanine and GABA metabolism. Data obtained from RNAseq libraries of soybean roots under hypoxic stress. Cultivars BR4 and E45 - Times of stress ( $0.5 \mathrm{~h}, 4 \mathrm{~h}$, and $28 \mathrm{~h})$. The respective genes were analyzed comparing the hypoxia stress treatment to the control, at each time-point, and generating fold change values. Red/blue means up/down regulated respectively.

\begin{tabular}{|c|c|c|c|c|c|c|c|c|}
\hline GENE ID V1.1 & GENE ID V2.0 & BR4_30min & BR4_4h & BR4_28h & E45_30min & E45_4h & E45_28h & Description NCBI \\
\hline Glyma01g41990 & Glyma.01G211000 & _ & _ & -2.98 & _ & -2.59 & -6.91 & acid beta-fructofuranosidase-like \\
\hline Glyma11g03360 & Glyma.11G030800 & _- & - & -8.88 & _ & -9.49 & -20.42 & acid beta-fructofuranosidase-like \\
\hline Glyma17g14750 & Glyma.17G138500 & - & - & -9.02 & - & -6.88 & -15.4 & acid beta-fructofuranosidase \\
\hline Glyma05g04290 & Glyma.05G056300 & - & -3.78 & - & - & - & - & acid beta-fructofuranosidase \\
\hline Glyma07g36440 & Glyma.07G236000 & _- & - & -2.23 & - & _ & -2.58 & alkaline/neutral invertase $\mathrm{A}$, mitochondrial-like \\
\hline Glyma10g28640 & Glyma.10G145600 & - & -4.62 & - & _ & _ & -2.57 & alkaline/neutral invertase A, mitochondrial-like \\
\hline Glyma17g04160 & Glyma.17G037400 & - & & -2.15 & - & _ & -2.54 & alkaline/neutral invertase $\mathrm{A}$, mitochondrial \\
\hline Glyma20g22780 & Glyma.20G095200 & - & -14.79 & -2.63 & _ & -2.64 & -2.5 & alkaline/neutral invertase $\mathrm{A}$, mitochondrial-like \\
\hline Glyma06g 47640 & Glyma.06G318500 & - & - & - & -3.8 & - & - & beta-fructofuranosidase, soluble isoenzyme I-like \\
\hline Glyma09g36580 & Glyma.09G231500 & _- & 3.48 & _ & _ & _ & -3.23 & beta-fructofuranosidase, soluble isoenzyme I-like \\
\hline Glyma12g00780 & Glyma.12G005100 & - & & 4.43 & 5.48 & -3.3 & 9.35 & beta-fructofuranosidase, soluble isoenzyme I-like \\
\hline Glyma14g11000 & Glyma.14G096600 & -2.04 & -12.94 & - & _ & -2.32 & _- & beta-fructofuranosidase, insoluble isoenzyme CWINV6-like \\
\hline Glyma19g38160 & Glyma.19G195400 & 4.12 & -4.78 & -7.78 & 9.45 & - & _ & beta-fructofuranosidase, insoluble isoenzyme CWINV6-like \\
\hline Glyma07g01090 & Glyma.07G008800 & - & -9.47 & - & - & -7.84 & - & beta-fructofuranosidase \\
\hline Glyma08g20490 & Glyma.08G192000 & 4.32 & 20.81 & 7.25 & 5.25 & 11.1 & 3.72 & beta-fructofuranosidase, cell wall isozyme-like \\
\hline Glyma13g42530 & Glyma.13G349300 & - & 3.25 & 24.4 & _ & 5 & 5.71 & beta-fructofuranosidase, cell wall isozyme-like \\
\hline Glyma15g02850 & Glyma.15G024600 & 20.79 & 12.08 & 69.82 & 22.54 & 10.35 & 26.31 & beta-fructofuranosidase, cell wall isozyme-like \\
\hline
\end{tabular}

\begin{tabular}{|c|c|c|c|c|c|c|c|c|}
\hline GENE ID V1.1 & GENE ID V2.0 & BR4_30min & BR4_4h & BR4_28h & E45_30min & E45_4h & E45_28h & Description NCBI \\
\hline Glyma09g08550 & Glyma.09G073600 & 2.03 & 9.63 & 2.69 & 2.45 & 14.04 & 5.88 & sucrose-6-phosphate synthase \\
\hline Glyma13g17421 & Glyma.13G114000 & - & 3.19 & - & - & 4.39 & - & Sucrose synthase \\
\hline Glyma13g23060 & Glyma.13G161600 & _- & 2.37 & _ & _- & - & _ & Sucrose synthase \\
\hline Glyma15g20180 & Glyma.15G182600 & 4.43 & 34.26 & 3.95 & 3.33 & 16.74 & 4.34 & Sucrose synthase \\
\hline Glyma17g05067 & Glyma.17G045800 & & 2.02 & & - & 2.18 & & Sucrose synthase \\
\hline Glyma14g03300 & Glyma.14G029100 & -2.66 & - & -11.5 & - & - & -14.94 & Sucrose synthase \\
\hline Glyma15g16171 & Glyma.15G151000 & - & - & - & - & - & -2.67 & Sucrose synthase \\
\hline Glyma17g11820 & Glyma.17G109700 & - & -2.24 & - & - & _ & - & Sucrose synthase \\
\hline Glyma06g48200 & Glyma.06G323700 & & & - & & -2.3 & 6.12 & sucrose-6-phosphate synthase \\
\hline Glyma08g42140 & Glyma.08G308600 & -2.64 & -4.44 & _ & -2.19 & -2.33 & - & sucrose-6-phosphate synthase \\
\hline Glyma20g16990 & Glyma.20G070500 & & -2.53 & -2.03 & & & & sucrose-6-phosphate synthase \\
\hline
\end{tabular}

\begin{tabular}{ccccccccc} 
ALANINE AMINOTRANSFERASE & & & & \\
\hline GENE ID V1.1 & GENE ID V2.0 & BR4_30min & BR4_4h & BR4_28h & E45_30min & E45_4h & E45_28h & Description NCBI \\
\hline Glyma07g05130 & Glyma.07G045900 & $\mathbf{5}$ & 13.4 & 16.19 & 7.14 & 14.16 & 12.32 & AlaAT - alanine aminotransferase \\
Glyma02g04320 & Glyma.02G038100 & - & -2.62 & - & - & -2.3 & -2.31 & AlaAT - alanine aminotransferase \\
\hline
\end{tabular}

\section{ASPARTATE AMINOTRANSFERASE}

\begin{tabular}{lccccccccc}
\hline GENE ID V1.1 & GENE ID V2.0 & BR4_30min & BR4_4h & BR4_28h & E45_30min & E45_4h & E45_28h & Description NCBI \\
\hline Glyma06g08670 & Glyma.06G082400 & - & 6.99 & 4.05 & 2.68 & 4.5 & 3.79 & Aspartate Aminotransferase \\
Glyma14g13480 & Glyma.14G111800 & 14.49 & 54.2 & 50.66 & 9.88 & 43.92 & 76.53 & Aspartate Aminotransferase \\
Glyma17g33050 & Glyma.17G216000 & 3.59 & 15.16 & 11.41 & 2.91 & 11.04 & 8.09 & Aspartate Aminotransferase \\
\hline
\end{tabular}

\section{GLUTAMATE SYNTHASE}

\begin{tabular}{ccccccccc}
\hline GENE ID V1.1 & GENE ID V2.0 & BR4_30min & BR4_4h & BR4_28h & E45_30min & E45_4h & E45_28h & Description NCBI \\
\hline Glyma4g41540 & Glyma.04G236900 & - & - & 2.44 & - & - & 3.04 & GLUTAMATO - Glutamate synthase (GOGAT) \\
Glyma19g16486 & Glyma.19G065600 & - & 6.89 & 6.35 & - & 6.84 & 5.52 & GLUTAMATO - Glutamate synthase (GOGAT) \\
\hline
\end{tabular}

\section{Statistical analysis}

See Tables 4 and 5. 
Table 4

Resume of variance analysis for metabolites identified in leaves. (SV) Source of Variation; (DF) Degrees of freedom. (DAF) Days after flooding.

\begin{tabular}{|c|c|c|c|c|c|c|c|c|c|c|c|c|c|c|}
\hline \multirow[t]{2}{*}{ S.V } & \multirow[t]{2}{*}{ D.F } & \multicolumn{3}{|c|}{ Carbohidrates } & \multicolumn{5}{|c|}{ Organic acids } & \multicolumn{5}{|c|}{ Amino acids } \\
\hline & & Sucrose & Fructose & Glucose & Acetate & Citrate & Succinate & Fumarate & Malate & Alanine & Gaba & Choline & Pinitol & Trigonelline \\
\hline \multicolumn{15}{|c|}{ Mean square (MS) 2 DAF } \\
\hline G & 1 & 0.001055 & 0.180983 & 1.111364 & 0.000036 & 0.007159 & 0.00013 & 0.041513 & $1.90045^{*}$ & $0.000686^{*}$ & 0.000101 & $0.006134^{*}$ & 0.041196 & 0.000011 \\
\hline WC & 1 & 0.002349 & 0.017457 & 0.054392 & 0.000151 & 0.539455 & 0.000295 & 0.155952 & $11.04442^{*}$ & $0.001385^{*}$ & $0.011495^{*}$ & 0.001636 & 0.010878 & 0.000041 \\
\hline$G^{*} W C$ & 1 & 0.003337 & 0.178535 & 0.025089 & 0.000016 & 0.00907 & 0.000845 & 0.001629 & 0.628056 & 0.000268 & 0.001523 & 0.000559 & 0.787508 & 0.000295 \\
\hline Error & 8 & 0.002615 & 0.052895 & 2.498878 & 0.000055 & 0.005275 & 0.000196 & 0.008096 & 0.149417 & 0.000032 & 0.000392 & 0.000662 & $0.109505^{*}$ & 0.000075 \\
\hline CV & & 20.96 & 11.95 & 15.9 & 10.39 & 13.67 & 12.93 & 17.22 & 13.31 & 10.04 & 13.01 & 11.8 & 13.44 & 12.61 \\
\hline Mean & & 0.0862417 & 1.924775 & 3.5157917 & 0.0715833 & 0.5313583 & 0.108225 & 0.5226 & 2.9046 & 0.0561083 & 0.15205 & 0.2180417 & 2.4617083 & 0.068575 \\
\hline \multicolumn{15}{|c|}{ Mean square (MS) 7 DAF } \\
\hline G & 1 & $0.03596^{*}$ & $1.123571^{*}$ & 0.134747 & 0.000006 & 0.196634 & $0.0048^{*}$ & $0.015783^{*}$ & 0.291383 & $0.005768^{*}$ & 0.000577 & 0.002241 & 0.209881 & 0.001372 \\
\hline WC & 1 & 0.00071 & $1.673355^{*}$ & $3.84495^{*}$ & $0.000837^{*}$ & $1.586969^{*}$ & 0.00122 & $0.167986^{*}$ & 17.853188 & $0.04619^{*}$ & 0.007272 & $0.023444^{*}$ & $1.176254^{*}$ & $0.000635^{*}$ \\
\hline $\mathrm{G}^{*} \mathrm{WC}$ & 1 & 0.000589 & $0.86559^{*}$ & $2.16682^{*}$ & 0.000012 & $0.495036^{*}$ & 0.003523 & $0.038715^{*}$ & 0.847434 & $0.006389^{*}$ & 0.000144 & 0.001801 & $1.083723^{*}$ & 0.000008 \\
\hline Error & 8 & 0.001097 & $0.021838^{*}$ & 0.040782 & 0.000042 & 0.004671 & 0.000785 & 0.002896 & 0.360963 & 0.000041 & 0.000241 & 0.000437 & 0.043628 & 0.000055 \\
\hline $\mathrm{CV}$ & & 0.046032 & 9.77 & 7.76 & 9.47 & 9.6 & 18.79 & 11.34 & 20.65 & 5.93 & 16.08 & 9.28 & 8.92 & 11.44 \\
\hline Mean & & 23.19 & 1.5128083 & 2.5371167 & 0.0681833 & 0.7121 & 0.1490833 & 0.47465 & 2.9100767 & 0.1082917 & 0.0966167 & 0.22545 & 2.3420833 & 0.0650083 \\
\hline \multicolumn{15}{|c|}{ Mean square (MS) 12 DAF } \\
\hline G & 1 & 0.002239 & $2.011955^{*}$ & $0.144256^{*}$ & $0.000766^{*}$ & $0.063948^{*}$ & $0.000249^{*}$ & 0.012078 & $0.700592^{*}$ & $0.000888^{*}$ & $0.002688^{*}$ & $0.009269^{*}$ & $4.113606^{*}$ & $1.20 \mathrm{E}-07$ \\
\hline WC & 1 & $0.007346^{*}$ & 10.360208 & 37.628438 & $0.001848^{*}$ & $0.035317^{*}$ & $0.000328^{*}$ & 0.152258 & 0.07904 & $0.018236^{*}$ & $0.042721^{*}$ & $0.099791^{*}$ & $7.98293^{*}$ & $0.000131^{*}$ \\
\hline$G^{*} W C$ & 1 & $0.005577^{*}$ & 0.0823669 & $0.782903^{*}$ & $0.000448^{*}$ & $0.029284^{*}$ & 0.000073 & 0.007455 & $0.405132^{*}$ & $0.000372^{*}$ & $0.002766^{*}$ & $0.003616^{*}$ & $0.807097^{*}$ & 0.000484 \\
\hline Error & 8 & 0.000535 & 0.060403 & 0.025487 & 0.000025 & 0.001166 & 0.000021 & 0.00363 & 0.007464 & 0.000035 & $0.000175^{*}$ & 0.001298 & 0.027105 & 0.000006 \\
\hline $\mathrm{CV}$ & & 18.34 & 10.62 & 4.17 & 6.31 & 9.04 & 5.44 & 11.2 & 2.71 & 6.16 & 8.62 & 4.31 & 4.91 & 3.46 \\
\hline Mean & & 0.126075 & 2.31355 & 3.827625 & 0.07875 & 0.3777167 & 0.0848583 & 0.5379583 & 3.1893538 & 0.0955167 & 0.1535833 & 0.295325 & 3.3559417 & 0.07295 \\
\hline
\end{tabular}

${ }^{*} P$ value $<0.05$. 
Table 5

Resume of variance analysis for metabolites identified in roots. (SV) Source of Variation; (DF) Degrees of freedom. (DAF) Days after flooding.

\begin{tabular}{|c|c|c|c|c|c|c|c|c|c|c|c|c|c|c|c|c|c|}
\hline \multirow[t]{2}{*}{ S.V } & \multirow[t]{2}{*}{ D.F } & \multicolumn{4}{|c|}{ Carbohidrates } & \multicolumn{5}{|c|}{ Organic acids } & \multicolumn{4}{|c|}{ Amino acids } & \multicolumn{3}{|c|}{ Isoflavones } \\
\hline & & Sucrose & Fructose & Glucose & Trehalose & Acetate & Citrate & Succinate & Fumarate & Malate & Alanine & Gaba & Choline & Pinitol & Malonyl & Daidzin & Daidzein \\
\hline \multicolumn{18}{|c|}{ Mean square (MS) 2 DAF } \\
\hline G & 1 & $2.074509^{*}$ & 0.03017 & 0.012832 & 0.000016 & $0.00081^{*}$ & 0.090446 & $0.004784^{*}$ & 0.000375 & 0.94905 & $0.036587^{*}$ & $0.008889^{*}$ & $0.002217^{*}$ & $0.160545^{*}$ & $768^{*}$ & $990.08^{*}$ & $10034.08^{*}$ \\
\hline WC & 1 & $5.326935^{*}$ & 0.006538 & 0.010215 & $0.00121^{*}$ & $0.22897^{*}$ & $4.029611^{*}$ & $0.423151^{*}$ & 0.00839 & 0.063817 & $0.213227^{*}$ & $0.077281^{*}$ & 0.002152 & 0.008933 & 85.3333 & 6.7500 & 2610.7500 \\
\hline$G^{*} W C$ & 1 & 0.315382 & 0.039159 & 0.004536 & 0.000012 & $0.00878^{*}$ & 0.02905 & 0.000791 & 0.000587 & 0.562424 & 0.032054 & 0.007651 & 0.000118 & 0.030281 & $341.333^{*}$ & 36.7500 & 3502.0833 \\
\hline Error & 8 & 0.010462 & 0.017854 & 0.005249 & 0.000014 & 0.000125 & 0.059832 & 0.000321 & 0.000038 & 0.052094 & 0.000073 & 0.000084 & 0.000465 & 0.00567 & 25.5000 & 45.9167 & 1702.7500 \\
\hline $\mathrm{CV}$ & & 6.09 & 9.38 & 9.74 & 7.2 & 2.89 & 12.88 & 3.5 & 9.41 & 6.85 & 4.45 & 6.19 & 2.62 & 7.64 & 12.42 & 33.19 & 19.02 \\
\hline Mean & & 1.6808 & 1.4248583 & 0.7435325 & 0.0513917 & 0.3872 & 1.8997 & 0.5117333 & 0.0655083 & 3.3315583 & 0.1919333 & 0.14815 & 0.2904917 & 0.9851167 & 40.6667 & 20.4167 & 216.9167 \\
\hline \multicolumn{18}{|c|}{ Mean square (MS) 7 DAF } \\
\hline G & 1 & $0.501925^{*}$ & $0.370797^{*}$ & 0.007213 & $0.000275^{*}$ & $0.006585^{*}$ & $0.596525^{*}$ & $0.168626^{*}$ & $0.002174^{*}$ & $5.215459^{*}$ & $0.009369^{*}$ & 0.000074 & 0.005096 & 0.060265 & $0.04308^{*}$ & $0.0186^{*}$ & 0.0000 \\
\hline WC & 1 & $12.76584^{*}$ & $0.697068^{*}$ & 0.160916 & $0.000365^{*}$ & $0.784948^{*}$ & $3.036007^{*}$ & $1.906663^{*}$ & 0.006098 & $1.235914^{*}$ & 0.152934 & $0.104963^{*}$ & 0.005432 & 0.008122 & $0.07192^{*}$ & 0.0180 & 0.0039 \\
\hline$G^{*} W C$ & 1 & 0.692256 & 0.039975 & 0.014255 & $3.33 \mathrm{E}-07$ & $0.002423^{\prime}$ & $0.994925^{*}$ & $0.057727^{*}$ & $0.001784^{*}$ & $3.269704^{*}$ & 0.011072 & 0.00012 & 0.000022 & 0.01068 & $0.027937^{*}$ & 0.0098 & 0.0121 \\
\hline ERROR & 8 & 0.30115 & 0.009245 & 0.002955 & 0.000018 & 0.002309 & 0.014116 & 0.001201 & 0.000014 & 0.085525 & 0.000095 & 0.000074 & 0.000095 & 0.049444 & 0.0001 & 0.0035 & 0.0066 \\
\hline $\mathrm{CV}$ & & 9.85 & 7.27 & 6.92 & 14.82 & 3.36 & 5.8 & 5.74 & 6.69 & 8.73 & 5.73 & 5.26 & 3.3 & 8.13 & 7.12 & 100.88 & 40.69 \\
\hline MEAN & & 1.7622167 & 1.32345 & 0.7859167 & 0.0282333 & 0.5055917 & 2.049417 & 0.6037583 & 0.055275 & 3.3488583 & 0.1700583 & 0.163375 & 0.2958917 & 0.96735 & 0.1278 & 0.0583 & 0.1998 \\
\hline \multicolumn{18}{|c|}{ Mean square (MS) 12 DAF } \\
\hline G & 1 & $0.46409^{\circ}$ & 0.000766 & 0.017055 & $9.08 \mathrm{E}-07$ & $0.002491^{*}$ & 0.025098 & $0.010878^{*}$ & 0.000216 & $0.518918^{*}$ & 0.000079 & $0.007071^{*}$ & 0.000137 & $0.06771^{*}$ & $0.00517^{*}$ & 0.018644 & 0.0010 \\
\hline WC & 1 & 2.904876 & 0.003913 & $0.117889^{*}$ & 0.000072 & $0.248803^{*}$ & 8.176082 & 0.33137 & $0.001793^{*}$ & $0.370516^{*}$ & $0.007767^{*}$ & $0.022197^{*}$ & $0.008705^{*}$ & $0.570201^{*}$ & $0.001141^{*}$ & 0.00696 & $0.1198^{*}$ \\
\hline$G^{*} W C$ & 1 & $1.157973^{\prime \prime}$ & 0.025604 & 0.001875 & 0.000031 & $0.026725^{*}$ & 0.001434 & $0.018229^{*}$ & $0.000068^{*}$ & $0.1565^{*}$ & $0.001178^{*}$ & $0.001494^{*}$ & 0.00012 & $0.06777^{*}$ & 0.002914 & $0.005941^{*}$ & 0.0075 \\
\hline Error & 8 & 0.007663 & 0.007938 & 0.006681 & 0.000038 & 0.000169 & 0.026335 & 0.000327 & 0.000056 & 0.019594 & 0.000035 & 0.000042 & 0.000073 & 0.002028 & 0.0001 & 0.0003 & 0.0097 \\
\hline $\mathrm{CV}$ & & 6.89 & 7.86 & 11.36 & 23.58 & 3.9 & 11.89 & 5.5 & 8.54 & 6.86 & 6.03 & 3.97 & 3.01 & 4.65 & 9.35 & 27.23 & 37.83 \\
\hline Mean & & 1.2709258 & 1.133225 & 0.71955 & 0.0260917 & 0.333475 & 1.3649667 & 0.328575 & 0.0310917 & 2.0397 & 0.009302 & 0.162525 & 0.28395 & 0.9680833 & 0.0816 & 0.0673 & 0.2608 \\
\hline
\end{tabular}

${ }^{*} P$ value $<0.05$ 


\section{Acknowledgments}

This work was supported by grants from the São Paulo Research Foundation (FAPESP), São Paulo Brazil I.D.C. fellowship, process 2015/21388-2. Brazilian Agricultural Research Corporation (EMBRAPA) and National Council for Scientific and Technological Development (CNPq). The assistance provided by the NuBBE group of São Paulo State University (UNESP) for the LC-MS/MS measurements is also acknowledged.

\section{Transparency document. Supporting information}

Transparency data associated with this article can be found in the online version at https://doi.org/ 10.1016/j.dib.2018.09.122.

\section{References}

[1] I.D. Coutinho, L.M.M. Henning, S.A. Döpp, A. Nepomuceno, A.C. Moraes, J. Marcolino-Gomes, C. Richter, H. Schwalbe, L. A. Colnago, Flooded soybean metabolomic analysis reveals importante primary and secondary metabolites involved in the hypoxia stress response and tolerance, Environ. Exp. Bot. 153 (2018) 176-187.

[2] D.I. Corol, C. Harflett, M. Beale, J.L. Ward, An efficient high throughput metabotyping platform for screening of biomass willows, Metabolites 4 (2014) 946-976.

[3] K. Zangger, Pure shift NMR, Prog. Nucl. Magn. Resonance Spectrosc. 86-87 (2014) 1-2015.

[4] M. Foroozandeh, R.W. Adams, N.J. Meharry, D. Jeannerat, M. Nilsson, G.A. Morris, NMR ultrahigh-resolution spectroscopy, Angew. Chem. 53 (2014) 6990-6992.

[5] T.J. Nakayama, F.A. Rodrigues, N. Neumaier, F.C. Marcelino-Guimarães, J.R.B. Farias, M.C.N. Oliveira, A. Borém, A.C.B. Oliveira, B.M. Emygdio, A.L. Nepomuceno, Reference genes for quantitative real-time polymerase chain reaction studies in soybean plants under hypoxic conditions, Genet. Mol. Res. 13 (2014) 860-871.

[6] M.D. Robinson, D.J. McCarthy, G.K. Smyth, edgeR: a Bioconductor package for differential expressionanalysis of digital gene expression data, Bioinformatics, 26 (2010) 139-140. https://doi.org/10.1093/bioinformatics/btp616. PMID: 19910308.

[7] Y. Benjamini, Y Hochberg, Controlling the false discovery rate: a practical and powerful approach to multipletesting, J. R. Stat. Soc., 1995, pp. 289-300. https://doi.org/10.2307/2346101.

[8] C. Williams, Flavone and flavonol O-glycosides. In: O. Andersen, K. Markham (Eds.), Flavonoids: chemistry, biochemistry, and applications, Florida, USA, 2006, pp. 897-950. 